\title{
Novel inflammatory cell infiltration scoring system to investigate healthy and footrot affected ovine interdigital skin.
}

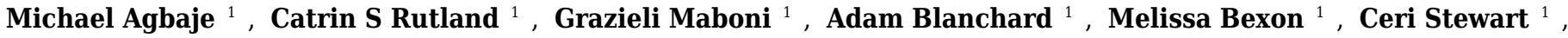 \\ Michael A Jones ${ }^{1}$, Sabine Totemeyer Corresp. 1 \\ ${ }^{1}$ School of Veterinary Medicine and Science, University of Nottingham, Nottingham, United Kingdom \\ Corresponding Author: Sabine Totemeyer \\ Email address: sabine.totemeyer@nottingham.ac.uk
}

Ovine footrot is a degenerative disease of sheep feet leading to the separation of hoofhorn from the underlying skin and lameness. This study quantitatively examined histological features of the ovine interdigital skin as well as their relationship with proinflammatory cytokine (IL-1 $\beta$ ) and virulent Dichelobacter nodosus in footrot. From 55 healthy and 30 footrot ovine feet, parallel biopsies (one fixed for histology) were collected post-slaughter and analysed for lesions and histopathological analysis using haematoxylin and eosin and Periodic Acid-Schiff. Histological lesions were similar in both conditions while inflammatory scores mirror IL-1 $\beta$ expression levels. Increased inflammatory score corresponded with high virulent $D$. nodosus load and was significant $(p<0.0001)$ in footrot feet with an inflammatory score of 3 compared to scores 1 and 2 . In addition, in contrast to healthy tissues, localisation of eubacterial load extended beyond follicular depths in footrot samples. The novel inflammatory cell infiltration scoring system in this study may be used to grade inflammatory response in the ovine feet and demonstrated an association between severity of inflammatory response and increased virulent $D$. nodosus load. 
1 Novel inflammatory cell infiltration scoring system to investigate healthy and footrot affected 2 ovine interdigital skin.

3

4 Michael Agbaje*, Catrin. S. Rutland*, Grazieli Maboni, Adam Blanchard, Melissa Bexon, Ceri

5 Stewart, Michael. A. Jones, Sabine Tötemeyer.

6

$7 \quad$ *Joint first authorship

8 +corresponding author: Sabine Tötemeyer: Sabine.totemeyer@nottingham.ac.uk

9

10 School of Veterinary Medicine and Science, Sutton Bonington Campus, University of Nottingham, 11 Nottingham, UK.

12

13

14 


\section{Abstract}

16 Ovine footrot is a degenerative disease of sheep feet leading to the separation of hoof-horn from

17 the underlying skin and lameness. This study quantitatively examined histological features of the

18 ovine interdigital skin as well as their relationship with pro-inflammatory cytokine (IL-1 $\beta$ ) and 19 virulent Dichelobacter nodosus in footrot. From 55 healthy and 30 footrot ovine feet, parallel 20 biopsies (one fixed for histology) were collected post-slaughter and analysed for lesions and 21 histopathological analysis using haematoxylin and eosin and Periodic Acid-Schiff. Histological

22 lesions were similar in both conditions while inflammatory scores mirror IL-1 $\beta$ expression levels.

23 Increased inflammatory score corresponded with high virulent $D$. nodosus load and was significant $24(\mathrm{p}<0.0001)$ in footrot feet with an inflammatory score of 3 compared to scores 1 and 2 . In addition, 25 in contrast to healthy tissues, localisation of eubacterial load extended beyond follicular depths in 26 footrot samples. The novel inflammatory cell infiltration scoring system in this study may be used 27 to grade inflammatory response in the ovine feet and demonstrated an association between severity 28 of inflammatory response and increased virulent $D$. nodosus load.

\section{Introduction}

30 Lameness in sheep, caused by interdigital dermatitis (ID) and footrot, is widespread in the UK, 31 having a major welfare and economic impact. Footrot is caused by Dichelobacter nodosus which 32 occurs in both virulent and benign forms. Footrot is defined by separation of the hoof from the 33 underlying structures and an accumulation of necrotic material, with varying degrees of severity 34 (Beveridge 1941; Thomas 1962), this damage is believed to be mediated by immune pathology 35 rather than by bacterial enzymes and toxins (Egerton et al. 1969).

36 Footrot development is characterised by invasion of neutrophils and lymphocytes into the dermis 37 and epidermis in response to bacterial invasion of the epidermis (Davenport et al. 2014; Egerton 
38 et al. 1969). Early histological studies described footrot as a degenerative condition of the stratum

39 granulosum and spinosum which results in cellular degeneration (cell ballooning), formation of

40 micro-abscesses and vacuoles which coalesce and progress to cavities (Beveridge 1941; Deane \&

41 Jensen 1955; Thomas 1962). A recent histological study of clinically healthy and affected feet

42 showed a progressive increase in lymphocyte and neutrophil infiltration into the dermis and

43 epidermis between healthy, ID and footrot samples (Davenport et al. 2014). In footrot samples,

44 purulence was seen in areas of epidermal degeneration, necrosis and epidermal-dermal clefts. As

45 in previous studies, cytoplasmic ballooning and nuclear condensation were observed in the stratum

46 spinosum of the epithelium (Thomas 1962), as well as areas of fibrosis indicating a chronic

47 reaction to tissue damage (Egerton et al. 1969).

48 Recently, we have shown that IL-1 $\beta$ and CXCL-8, but not IL-6 and IL-17 mRNA expression levels

49 correlate with D nodosus load in footrot samples (Maboni et al 2017). In addition, stimulation of

50 ex vivo organ explant of ovine interdigital skin infected with $D$ nodosus elicited IL-1 $\beta$ release

51 (Maboni et al. 2017b).

52 The aim of this study was to perform a qualitative and quantitative analysis of histopathological

53 features of the ovine interdigital skin comparing healthy and footrot affected feet. In order to

54 evaluate inflammation in the epidermis and dermis a novel scoring system was developed and

55 correlation of those scores with the expression of the pro-inflammatory cytokine IL-1 $\beta$ and $D$

56 nodosus load was investigated. In addition the depth of within tissue colonisation of eubacteria, $D$

57 nodosus and $F$ necrophorum were examined in the context of hair follicle depth.

58 Materials and Methods

59 Ovine biopsies 
60 Samples of ovine feet were obtained post-slaughter from an abattoir and assessed by two

61 independent scorers for conformation and clinical conditions (healthy and footrot affected).

62 Conformation scoring was assessing the integrity of the sole and heel/wall of each digit: $0=$

63 undamaged sole and heel area with a perfect shape. $1=$ mildly damaged $/ \mathrm{misshapen}$ sole and/or

64 heel area of the digit $(<25 \%) .2=$ moderately damaged $/$ misshapen sole and $/$ or heel area of the

65 digit $(>25 \%$ and $<75 \%) .3=$ severely damaged $/ \mathrm{misshapen} \mathrm{sole} \mathrm{and} /$ or heel area of the digit $(>$

66 75\%) (Maboni et al 2016). Ovine feet were scored as described previously (Kaler et al. 2010)

67 with healthy defined as an absence of any interdigital skin lesion and footrot as the presence of

68 underrunning lesions. Roughage, faeces and mud were removed from the interdigital space of

69 each foot and prior to biopsy taking the skin was wiped with $70 \%$ ethanol. Biopsies of $6 \mathrm{~mm}$

70 diameter ( $\mathrm{n}=85$ ) were taken using a punch biopsy tool (National Veterinary Services, UK) in the

71 interdigital space along the skin-hoof interface, of which 55 were from interdigital skin without

72 signs of disease and 30 from feet with footrot.

$73 \quad$ Histological sample preparation

74 Preparation was as previously described (Maboni et al. 2017a), in brief all samples were fixed

75 using $10 \%(\mathrm{v} / \mathrm{v})$ neutral buffered formalin; however to obtain optimal tissue integrity healthy

76 biopsies were fixed for 48 hours at $4{ }^{\circ} \mathrm{C}$ and footrot biopsies for 24 hours at room temperature

77 (fixation and processing were optimised using two fixatives $(10 \% \mathrm{v} / \mathrm{v}$ neutral buffered formalin

78 verses $4 \% \mathrm{v} / \mathrm{v}$ paraformaldehyde), two incubation temperatures (room temperature verses $4^{\circ} \mathrm{C}$ )

79 and two incubation times ( 24 hours verses 48 hours). An extended tissue processing protocol was

80 used (60 minutes in $\mathrm{dH}_{2} \mathrm{O}, 4$ hours in 50\% ethanol, 4 hours in $70 \%$ ethanol, 16 hours in $90 \%$

81 ethanol, 4 hours in 100\% ethanol, $4 \mathrm{~h}$ in Xylene) followed by embedding into paraffin wax ( 2 hours,

$\left.8260^{\circ} \mathrm{C}\right)$. Paraffin wax embedded tissues were soaked in $10 \%(\mathrm{v} / \mathrm{v})$ ammoniated water and $6 \mu \mathrm{m}$ thick 
83 sections were cut from each block by microtome (Leica RM2255, Germany). Serial sections were

84 mounted on polysilinated microscope glass slides (Thermo-Scientific, Menzel Gläser Polysine ${ }^{\circledR}$,

85 Germany) and dried at room temperature overnight.

86 Tissue staining

87 Paraffin sections were heated at $60^{\circ} \mathrm{C}$ for 5-10 minutes, incubated in xylene twice for 5 minutes 88 each and rehydrated in $100 \%$ ethanol, $90 \%$ ethanol, $70 \%$ ethanol then twice in $\mathrm{dH}_{2} \mathrm{O}$ for 5 minutes 89 each. Protocols were optimized for haematoxylin and eosin (H\&E) and Periodic Acid-Schiff(PAS; 90 Sigma-Aldrich, UK). In brief H\&E stained samples received 2.5 minutes in haematoxylin, 15 91 seconds in $1 \%$ acetic industrial methylated spirits, 15 seconds in ammoniated water and 4 minutes 92 in eosin. The PAS stain included immersion in periodic acid-Schiff solution for 15 minutes, 93 haematoxylin for 3 minutes. Following each staining protocol sections were dehydrated through 94 an ethanol series.

\section{Image capture and analysis}

96 Each observer was blinded to the sample identification to avoid subconscious bias. Images were 97 captured using a Leica CTR500 microscope (Leica Microsystems, Germany) with bright field 98 light. For each sample, three sections approximately $400 \mu \mathrm{m}$ apart were analysed. At 40x 99 magnification, five non-overlapping photos were taken from each section from both the epidermis 100 (1,275 photomicrographs analysed) and the dermis (1,245 photomicrographs - two fragmented 101 dermal tissue sections were excluded) of H\&E stained sections and from the dermal-epidermal 102 junctions of PAS stained sections (1,275 photomicrographs analysed). In addition each sample 103 was viewed at 5x magnification and photomicrographs were merged in order to visualise entire 104 sections.

105 Tissue and cell scoring 
106 For each tissue sample, 15 photomicrographs were scored for inflammation. The maximum score

107 of five non-overlapping images from each of three slides per block was determined as the score

108 for that tissue sample. A score of 0 represented no leukocytes in photomicrograph, score 1

109 occasional infiltration of single leukocytes visible, score 2 focal infiltration of leukocytes, score 3

110 coalescing leukocytes - individual loci could not be distinguished, and score 4 diffuse infiltration

111 of leukocytes throughout the field of view. Examples of the epidermal and dermal scoring system

112 are shown in Figures 1 and 2, respectively. The scoring system was validated using two

113 independent scorers blinded to sample identification.

114 Parakeratosis was defined as the retention of nuclear remnants in the stratum corneum (Brady

115 2004). Grading in the interdigital skin stratum corneum was based on a three ordinal scale criteria

116 as: the absence of parakeratosis (score 0 ), the presence of focal parakeratosis (score 1) and diffuse

117 parakeratosis (score 2) (Fig. 3A-C).

118 Micro-abscesses were defined as the aggregation of inflammatory cells and cellular debris,

119 confined by fibrotic tissue walling. Grading was according to skin layer (intra-corneal, sub-corneal

120 and dermal (Fig. 3D-F)) and based on a nominal grading scale: presence/absence from 5 images

121 throughout each tissue section.

122 In order to determine the area of ballooned cells per cross sectional area in the epidermis,

123 photomicrographs were taken, saved in a Tagged Image File Format and uploaded into the analysis

124 software Image Pro 6.3 (Media Cybernetics, USA). Each image was calibrated for the

125 measurement of ballooned cells area in absolute values $\left(\mu \mathrm{m}^{2}\right)$. Ballooned cells were identified and

126 manually selected using the software to trace around each ballooned cell or group of cells.

127 Percentage area of ballooned cells per photomicrograph calculated (total area of ballooned

128 cell(s)/total area of epidermal cross section X 100, for example see Fig. 4A). 
129 Congestion was defined as presence of dilated blood capillaries with visible red blood cells

130 (erythrocytes) within the dermis and haemorrhage was defined as observed blood cells outside

131 capillaries in tissues (Fig. 4B-C). For both features, 15 photomicrographs were analysed per tissue

132 with a nominal grading scale: presence/absence.

133 Basement membrane integrity was assessed using PAS stained sections scored for basement

134 membrane disruptions at the dermal-epidermal junction as follows: score 0 no basement membrane

135 disruption identified, score 1 focal basement membrane disruption identified, score 2 multiple

136 basement membrane disruption identified (Fig. 4D-F).

137 The IL-1 $\beta$ expression and $D$ nodosus quantification data have been published previously (Maboni 138 et al. 2017a).

139 Bacterial localisation.

140 Tissue samples were briefly incubated in $70 \%$ ethanol followed by overnight incubation in $30 \%$

141 (w/v) sucrose and embedded in OCT (VWR International, Belgium). Alternating thick $(40 \mu \mathrm{m})$ and

142 thin $(9 \mu \mathrm{m})$ transverse sections were sectioned from the dermal layer across biopsies into the

143 epidermis. The cryostat blade was cleaned with $70 \%$ ethanol prior to each thick section in order to

144 prevent potential bacterial contamination. Thick sections intended for DNA extraction to

145 determine bacterial abundance were preserved in 0.5ml RNAlater ${ }^{\circledR}$ (Sigma-Aldrich, St. Luis,

146 USA) at room temperature and incubated overnight prior to DNA extraction. Corresponding

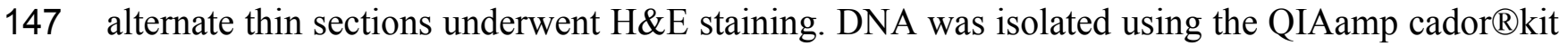

148 (QIAGEN) as described previously (Maboni et al. 2016). Bacterial load was quantified using 149 quantitative PCR as described previously for total eubacteria (Strub et al. 2007), D. nodosus

150 (Frosth et al. 2012) and F. necrophorum (Frosth et al. 2015). In order to compare bacterial

151 localisation and load across the same depth of skin layers across different samples, 11 bin groups 
152 representing skin depths from 0 to $2200 \mu \mathrm{m}$ (range $200 \mu \mathrm{m} / \mathrm{bin}$ ) were created. $\mathrm{N}=4$ healthy and 5

153 footrot samples.

154 Statistical analysis

155 Statistical analyses were performed on Graphpad Prism version 6 for Windows. Resulting data

156 were presented as frequencies and percentages. Categorical data within and between clinical

157 conditions were compared by Fisher's exact and Chi-square tests while continuous data were

158 analysed by Student T-test or Kruskal Wallis test, dependant on data distribution. Statistical data

159 on DNA samples was carried out using Pearson correlation. Analysis was taken as significant

160 when $\mathrm{p} \leq 0.05$.

$161 \quad$ Ethical approval

162 Ethical approval was obtained from the School of Veterinary Medicine and Science Ethics 163 committee, University of Nottingham (ethical approval number: 796 130128).

\section{Results}

165 To investigate the levels of inflammation within the interdigital skin, inflammation and occurrence

166 of micro-abscesses were scored separately in the epidermis and dermis. In addition, in the

167 epidermis, the area of ballooning was measured and the occurrence of parakeratosis was

168 determined, and in the dermis, occurrence of haemorrhages and congestion were determined. The

169 basement membranes were also assessed for disruptions.

170 In the epidermis, the same level of inflammation was observed in healthy $(\mathrm{n}=55)$ and footrot

$171(\mathrm{n}=30)$ samples with a median inflammation score 2 (minimum 1, maximum 4, Fig. 5A). In

172 addition, no differences between healthy and footrot samples were seen with regards to the area of

173 ballooned cells (Fig. 5B; $n=55$ and 30 respectively). The proportion of samples with intra-corneal

174 (healthy 43.64\%, 24/55 [95\%CI: 59-90.4\%] and footrot 33.33\% 10/30 [95\%CI: 27.2-73\%]) or 
175 sub-corneal (healthy 25.45\%, 14/55 [95\%CI: 20-50\%] and footrot 23.33\%, 7/30 [95\%CI: $13.2-$

$17653 \%$ ]) micro-abscesses were also not significantly different (Fig. 5C-D). Parakeratosis was also

177 observed to a very similar extent in both, healthy $(72.73 \%, 40 / 55$ [95\%CI: 59-84\%]) and footrot

178 (76.67\%, 23/30 [95\%CI: 58-90\%]) samples (Fig. 5E). However, while in footrot these were evenly

179 split into samples with diffuse and focal parakeratosis, two thirds of the healthy samples with

180 parakeratosis showed a diffuse pattern (Fig. 5E).

181 Basal membrane disruption was observed in 74.55\% (41/55 [95\%CI: $61-85.3 \%])$ healthy and

$18256.67 \%(17 / 30$ [95\%CI: 37.4-74.5\%]) footrot affected samples, with only a small proportion of

183 samples with multiple disruptions (Fig. 5F).

184 In the dermis, a higher maximum inflammation score of 3 (minimum 2, maximum 4) was seen in 185 healthy and footrot affected tissues (Fig. 6A; n=54 and 29 respectively). There was also no 186 difference between healthy and footrot affected tissues with regards to the proportion of samples 187 with dermal micro-abscesses, haemorrhages or congestion (Fig. 6B-D). Dermal micro-abscesses 188 were observed in $8.5 \%$ of the tissues, with 4 out of 50 healthy tissues $(7.41 \%$ [95\%CI: $2.2-19.2 \%])$ 189 and 3 out of 26 footrot affected tissues (10.34\% [95\%CI: 2.4-30.1\%]; Fig. 6B). Haemorrhages 190 were observed in approximately one third of samples of each disease state (Fig. 6C; healthy $191=30.91 \%, 17 / 50$ [95\%CI: 28.6-62\%], footrot $=30.00 \%, 9 / 30$ [95\%CI: 22-66\%]). A similar level 192 of congestion in blood vessels was found in clinically healthy $(49.00 \%, 27 / 55$ [95\%CI:81.6193 99.9\%]) and footrot samples (40.00\%, 12/30 [95\%CI: 41-86.6\%]) (Fig. 6D).

194 We have shown previously that mRNA expression of IL-1 $\beta$, similar to inflammation scores, were 195 comparable in healthy and footrot affected tissues in parallel samples from the same feet (Maboni 196 et al. 2017a). Here we analysed inflammatory scores, parakeratosis and presence of micro197 abscesses in the context of IL-1 $\beta$ mRNA expression. IL-1 $\beta$ expression was significantly higher in 
198 the presence of diffuse parakeratosis in healthy tissues with no difference in footrot affected tissues

199 (Fig. 7A-B; $\mathrm{n}=41$ healthy and 23 footrot, $\mathrm{p}<0.01$ ). When comparing relative IL-1 $\beta$ expression with

200 the inflammation scores they mirrored to an extent (Fig. 8).

201 Since footrot pathology is mediated by host inflammatory responses whilst the disease is initiated 202 by $D$. nodosus, virulent $D$. nodosus load against host inflammatory cells was compared in healthy 203 ( $\mathrm{n}=30$ for both epidermis and dermis) and affected tissues ( $\mathrm{n}=18$ epidermis and 17 dermis). 204 Inflammatory scores increased as virulent D. nodosus load increased (Fig. 9). In the epidermis, 205 virulent $D$. nodosus load was significantly higher $(\mathrm{p} \leq 0.0001)$ in tissues with an inflammatory score 206 of 3 compared to scores 1 and 2 respectively (Fig. 9B, Supplementary Fig. 1).

207 Bacterial localisation in ovine interdigital skin.

208 Eubacterial $D$. nodosus and F. necrophorum DNA was quantified across the entire skin depth. 209 Eubacterial load in healthy samples $(\mathrm{n}=5)$ was similar throughout the tissue depths but peaked at

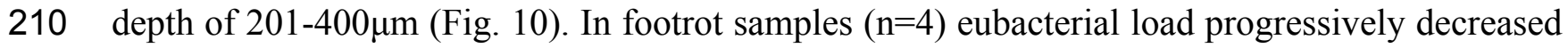
211 from the outermost skin surface to a depth of $1000 \mu \mathrm{m}$, eubacterial load was then similar from $212 \quad 1200-2200 \mu \mathrm{m}$.

213 In footrot samples, D. nodosus was quantified across depths of $601-2200 \mu \mathrm{m}$, whereas it was 214 detected throughout all levels of the healthy samples. F. necrophorum in healthy samples was 215 detected in deeper skin tissues $(601-2200 \mu \mathrm{m})$ but was present throughout every levels in footrot 216 samples (Fig. 10). The distribution pattern of eubacterial load in ovine interdigital skin samples 217 were investigated with respect to depth of skin sections in the context of depth of follicles in skin. 218 A relatively low eubacterial load of range of $0.4-19.6 \mathrm{pg} / \mathrm{section}$ was observed across healthy 219 samples. In comparison, footrot samples eubacterial load was higher in four out of five samples 220 with peak values of $1218 \mathrm{pg} /$ section observed in the superficial skin depth $(\leq 500 \mu \mathrm{m}$; Fig. 10). 
221 Localisation of eubacterial load did not extend beyond follicular depths $(2119-2710 \mu \mathrm{m})$ in healthy

222 samples while in footrot samples, eubacterial load extended beyond follicular depths (1460-

$2232699 \mu$ m; Fig. 10, Supplementary Fig. 2).

\section{Discussion}

225 In this study, histopathological features of the ovine interdigital skin were analysed and compared 226 between healthy and footrot affected feet using a novel scoring system. In addition, these features 227 were compared to levels of IL-1 $\beta$ and virulent $D$. nodosus. Of note in this study was the severity 228 of inflammatory cell infiltration that was found to be similar between healthy and footrot affected. 229 Inflammation in healthy samples may have been caused by unfavourable ground conditions of the 230 pasture due to wet weather. Under those condition previous studies have also noted an increase in 231 increase the prevalence of footrot and interdigital dermatitis (Beveridge 1941; Emery et al. 1984; 232 Graham \& Egerton 1968; Wassink et al. 2003; Wassink et al. 2004). Alternatively, inflammatory 233 cell infiltrations could be an indication of subclinical disease not yet progressed to visible signs of 234 ID and footrot.

235 Previous studies have qualitatively described mild inflammatory cell infiltration in healthy ovine 236 feet (Angell et al. 2015; Davenport et al. 2014). To the best of our knowledge, this is the first study 237 to quantitatively examine inflammatory cells in the ovine feet using a new scoring system. Similar 238 investigations in cattle also found inflammatory cell infiltration in apparently healthy hooves 239 (Mendes et al. 2013; Tarlton et al. 2002). However, Tarlton and colleagues attributed the 240 inflammatory response observed to the changes in collagen expression and keratinization of 241 epidermal laminae caused by intensive breeding regimes during the peripartum period (Tarlton et 242 al. 2002). Interestingly, bovine digital dermatitis, which is driven by inflammatory response in its 
243 pathogenesis, is also characterised by inflammatory cell infiltration (Mendes et al. 2013; Refaai et 244 al. 2013).

245 Histological lesions including cell ballooning, parakeratosis and micro-abscesses were similarly 246 observed in both conditions and in areas associated with pathology including inflammation in the 247 skin (Refaai et al. 2013). Cellular ballooning in the epidermis is an indication of host cell response 248 to stimuli and may be preceded by keratinocytes hyper-proliferating to remove pathogen infected 249 areas (sloughing) (Edwards et al. 2003). Hyper-proliferation of keratinocytes without a 250 corresponding rate of differentiation results in parakeratosis. This has been shown to occur in low 251 grade inflammation caused by microbial presence such as Fusobacterium necrophorum (Egerton 252 et al. 1969). Parakeratosis may trigger the release of pro-inflammatory cytokines such as IL-1 $\beta$ 253 (Chang et al. 1992) which in-turn mediates the recruitment of inflammatory cells. This may explain 254 the higher levels of IL-1 $\beta$ expression associated with diffuse parakeratosis in this study.

255 As expected, higher IL-1 $\beta$ expression levels corresponded with high epidermal inflammatory score 256 grade (score 4) when compared to lower score grade (score 1) in footrot but not in healthy feet. 257 This suggests that IL-1 $\beta$ expression level may be directly proportional to the severity of 258 inflammatory cell infiltrates in the epidermis. To investigate this further, future studies could 259 include immunohistochemical visualization of IL-1 $\beta$ protein in relation to cell infiltration or other 260 lesions. Similarly, significantly increased virulent D. nodosus loads tend to correspond with higher 261 epidermal inflammatory score grades (scores 2 and 3) when compared to lower grade (score 1) in 262 footrot but not healthy samples. This suggests that the severity of inflammatory response in footrot 263 is dependent on the abundance of virulent $D$. nodosus. This also confirms previous studies based 264 on severity and bacteria load (Maboni et al. 2017a; Maboni et al. 2016). The initiation of footrot 265 is mostly associated with virulent $D$. nodosus due to its ability to degrade host extracellular matrix, 
266 a trait conferred by the presence of the acidic protease AprV2. It is different from a second benign 267 phenotype which possess the acidic protease AprB2 (Kennan et al. 2010). Interestingly, not all 268 cases of virulent $D$. nodosus correlate to severe clinical manifestations since it has been reported 269 in apparently healthy feet without signs of ID or footrot (Maboni et al. 2016; Moore et al. 2005; 270 Stauble et al. 2014). In the UK, virulent D. nodosus has been reported as the predominant strain 271 (Maboni et al. 2016; Moore et al. 2005).

272 Studies using whole biopsies reported eubacteria presence in healthy ovine interdigital skin 273 (Calvo-Bado et al. 2011; Maboni et al. 2016; Witcomb et al. 2015). Interestingly, we detected 274 eubacterial DNA down to depths of $3 \mathrm{~mm}$ in healthy samples. A previous study of healthy human 275 skin also demonstrated eubacterial DNA in deep facial and palm skin tissues $(5 \mathrm{~mm})$, with 276 localisation including hair follicles and also dermal stroma (Nakatsuji et al. 2013).

277 As expected, eubacterial load was significantly higher in the outermost layer of footrot skin $278(\leq 200 \mu \mathrm{m})$ in comparison to the same depth in healthy samples. Other studies on a human skin 279 model have also reported higher bacteria abundance in the superficial layers of human skin (Lange280 Asschenfeldt et al. 2011; Roeckl \& Mueller 1959). Detection of bacteria DNA in deep layers of 281 healthy skin may indicate that the skin is not an impervious barrier as previously thought 282 (Nakatsuji et al. 2013).

283 Previous studies based on Giemsa stain and fluorescent in situ hybridisation (FISH) have suggested 284 D. nodosus was primarily localised in superficial epidermis of ovine interdigital skin (Egerton et 285 al. 1969; Witcomb et al. 2015). However, Witcomb and colleagues reported a single cell of $D$. 286 nodosus in the dermis of footrot infected ovine skin (Witcomb et al. 2015). In contrast to FISH, 287 qPCR technique is able to amplify target DNA, thereby detecting low levels of $D$. nodosus. 
288 Hair follicles have been reported to serve as a bacterial reservoir and hence, possible routes of

289 bacterial entry into healthy skin (Montes \& Wilborn 1970). The analysis of sequential transverse

290 sections in our study showed that eubacterial load corresponded to follicular depth in healthy

291 samples but extended beyond follicular depth in footrot samples. This suggests that hair follicles

292 may play a role in eubacteria localisation in intact healthy skin. In contrast, in a similar

293 polymicrobial disease of bovine feet, digital dermatitis, no association was found between

294 treponemes and hair follicles (Evans et al. 2009).

\section{Conclusions}

296 Data presented in this study showed for the first time that there are no consistent differences in the 297 level and range of histological lesions examined between healthy and footrot affected feet. 298 Interestingly, the novel inflammatory cell infiltration scoring system developed and validated in 299 this study mirrored the pro-inflammatory cytokine IL-1 $\beta$ and confirmed an association between 300 severity of inflammatory response and increased virulent $D$. nodosus load.

\section{Acknowledgements}

302 The authors thank Aziza Alibhai for her technical assistance with the histology as well as the 303 abattoir staff for assistance with sample collection.

\section{Figure Legends}

305 Figure 1: Descriptors of leukocyte cell infiltration in ovine interdigital skin epidermis.

306 Haematoxylin and eosin stained epidermis photomicrographs showing no leukocytes in

307 photomicrograph (A), occasional infiltration - single leukocytes visible within boxed areas (B),

308 focal infiltration of leukocytes - visible in boxed areas (C), coalescing leukocytes - individual

309 loci cannot be distinguished (D) and diffuse infiltration of leukocytes throughout the field of 
310 view (E). A-E represent inflammatory scores of $0-4$ respectively, $n=55$ healthy and 30 footrot.

311 Scale bars represent $50 \mu \mathrm{m}$.

312 Figure 2: Descriptors of leukocyte cell infiltration in ovine interdigital skin dermis.

313 Haematoxylin and eosin stained dermis photomicrographs showing no leukocytes in

314 photomicrograph (A), occasional infiltration of leukocytes (B), focal infiltration of leukocytes -

315 visible within boxed areas (C), coalescing leukocytes - individual loci cannot be distinguished

316 (D) and diffuse infiltration of leukocytes throughout the field of view (E). A-E represent

317 inflammatory scores $0-4$ respectively, $\mathrm{n}=54$ healthy and 29 footrot. Scale bars represent $50 \mu \mathrm{m}$.

318 Figure 3: Descriptors of parakeratosis and micro-abscesses in ovine interdigital skin.

319 Haematoxylin and eosin stained interdigital skin from healthy $(n=55)$ and footrot $(n=30)$ affected

320 sheep. Stratum corneum photomicrographs showing no nuclear remnants visible (A), focal

321 accumulation of nuclear remnants (B) and diffuse accumulation of nuclear remnants (C). A-C

322 represent parakeratosis scores $0-2$ respectively. Representative photomicrographs of micro-

323 abscesses from the intra-corneal (D), sub-corneal (E) and dermal layers (F). Scale bars represent

$32450 \mu \mathrm{m}$.

325 Figure 4: Interdigital skin cell ballooning, congestion and basement membrane integrity.

326 Haematoxylin and eosin stained sections from healthy $(\mathrm{n}=55)$ and footrot $(\mathrm{n}=30)$ affected sheep

327 showing representative cell balloon measurements (A), congestion (B) and haemorrhage (C).

328 PAS stained tissue shows basement membrane integrity scoring from 0 to 2 (D-E respectively).

329 Figure 5: Epidermal histological lesions of ovine interdigital skin basal membrane integrity.

330 Haematoxylin and eosin stained sections from 55 clinically healthy and 30 footrot tissue samples of

331 skin/hoof interface were evaluated with regards to inflammatory score (A), area of cell ballooning

332 (B), presence of intra-corneal micro-abscesses (C), presence of sub-corneal micro-abscess (D), 
333 parakeratosis score (E). PAS stained sections from the same tissues were scored for disruptions of

334 the basement membrane (F). The horizontal black line indicates median (A) and mean (B) values.

335 Blue bars indicate healthy and red bars indicate footrot affected samples. Statistical analysis: Fisher's

336 exact test (A, C-E) and one-way ANOVA (B).

337 Figure 6: Dermal histological lesions of ovine interdigital skin.

338 Haematoxylin and eosin stained sections from 55 clinically healthy and 30 footrot tissue samples of

339 skin/hoof interface were evaluated with regards to inflammatory score (A), presence of dermal

340 micro-abscesses (B) haemorrhages (C) and congested blood vessels (D). The horizontal black line

341 indicates median (A) values. Statistical analysis: Fisher's exact test.

342 Figure 7: Comparison between IL-1 $\beta$ mRNA expression and parakeratosis score in ovine

343 interdigital skin.

344 Correlation between IL-1 $\beta$ mRNA expression and parakeratosis score calculated from

345 Haematoxylin and eosin stained samples of skin/hoof interface using parallel sections from the

346 same interdigital space. $n=41$ clinically healthy and 23 footrot samples. Statistical analysis:

347 Pearson correlation $* * \mathrm{p}<0.01$.

348 Figure 8: Comparison between IL-1 $\beta$ mRNA expression and epidermal and dermal

349 inflammatory score in ovine interdigital skin.

350 Correlation between IL-1 $\beta$ mRNA expression and inflammatory score calculated from 351 Haematoxylin and eosin stained samples of skin/hoof interface using parallel sections from the 352 same interdigital space. $n=41$ clinically healthy and 23 footrot from the epidermis and 40 and 23 353 respectively from the dermis. Statistical analysis: Pearson correlation $* \mathrm{P}<0.05$.

354 Figure 9: Virulent $D$. nodosus DNA levels in comparison to inflammatory scores in epidermal 355 and dermal ovine interdigital skin. 
356 Correlation between epidermal and dermal inflammatory scores from healthy $(n=30)$ and footrot

357 samples ( $\mathrm{n}=18$ epidermis and 17 dermis) in comparison to $D$. nodosus levels. Statistical analysis:

358 Pearson correlation $* * * \mathrm{P}<0.0001$.

359 Figure 10: Bacterial localisation throughout skin layers.

360 Total DNA was extracted from sequential $40 \mu \mathrm{m}$ horizontal sections of $6 \mathrm{~mm}$ punch biopsies

361 from four healthy (A) and five footrot (B) affected tissue samples. Quantitative PCR was used to 362 enumerate total bacterial DNA and detect the presence or absence of D. nodosus and F.

363 necrophorum. Sections were grouped in $200 \mu \mathrm{m}$ bins.

364 Supplementary Figure 1: Virulent $D$. nodosus DNA levels in comparison to median

365 inflammatory scores in epidermal and dermal ovine interdigital skin.

366 Correlation between epidermal and dermal median inflammatory scores from healthy $(n=30)$ and

367 footrot samples ( $\mathrm{n}=18$ epidermis and 17 dermis) in comparison to D. nodosus levels. Statistical

368 analysis: Pearson correlation $* * * \mathrm{P}<0.0001$.

369 Supplementary Figure 2: Eubacterial load distribution within ovine interdigital skin in

370 relation to follicle depth.

371 Eubacterial load presented in individual sections at progressive depths of biopsy samples in four

372 healthy samples (A-D) and five footrot affected samples (E-I). Black vertical lines represent

373 depth $(\mu \mathrm{m})$ of follicles.

374

375 References

376

377

378

379

380

381

382
Angell JW, Crosby-Durrani HE, Duncan JS, Carter SD, and Blundell R. 2015. Histopathological Characterization of the Lesions of Contagious Ovine Digital Dermatitis and Immunolabelling of Treponema-like Organisms. J Comp Pathol 153:212-226. 10.1016/j.jcpa.2015.10.178

Beveridge WIB. 1941. Foot-Rot in Sheep: A Transmissible Disease due to Infection with Fusiformis Nodosus (N. Sp.). Studies on Its Cause, Epidemiology, and Control. In: Research BotCfSal, editor. Australia. p 1-58. 
383

384

385

386

387

388

389

390

391

392

393

394

395

396

397

398

399

400

401

402

403

404

405

406

407

408

409

410

411

412

413

414

415

416

417

418

419

420

421

422

423

424

425

426

427

428

429

430

431

432

433

Brady SP. 2004. Parakeratosis. Journal of the American Academy of Dermatology 50:77-84. 10.1016/S0190-9622(03)02801-9

Calvo-Bado LA, Oakley BB, Dowd SE, Green LE, Medley GF, UI-Hassan A, Bateman V, Gaze W, Witcomb L, Grogono-Thomas R, Kaler J, Russell CL, and Wellington EMH. 2011. Ovine pedomics: the first study of the ovine foot $16 \mathrm{~S}$ rRNA-based microbiome. Isme Journal 5:1426-1437. 10.1038/ismej.2011.25

Chang EY, Hammerberg C, Fisher G, Baadsgaard O, Ellis CN, Voorhees JJ, and Cooper KD. 1992. T-Cell Activation Is Potentiated by Cytokines Released by Lesional Psoriatic, but Not Normal, Epidermis. Archives of Dermatology 128:1479-1485. DOI 10.1001/archderm.128.11.1479

Davenport R, Heawood C, Sessford K, Baker M, Baiker K, Blacklaws B, Kaler J, Green L, and Totemeyer S. 2014. Differential expression of Toll-like receptors and inflammatory cytokines in ovine interdigital dermatitis and footrot. Vet Immunol Immunopathol 161:9098. 10.1016/j.vetimm.2014.07.007

Deane HM, and Jensen R. 1955. The pathology of contagious foot rot in sheep. Am J Vet Res 16:203-208.

Edwards AM, Dymock D, and Jenkinson HF. 2003. From tooth to hoof: treponemes in tissuedestructive diseases. Journal of Applied Microbiology 94:767-780. DOI 10.1046/j.13652672.2003.01901.x

Egerton JR, Roberts DS, and Parsonso.Im. 1969. Aetiology and Pathogenesis of Ovine Foot-Rot .I. A Histological Study of Bacterial Invasion. J Comp Pathol 79:207-\&. Doi 10.1016/00219975(69)90007-3

Emery DL, Stewart DJ, and Clark BL. 1984. The comparative susceptibility of five breeds of sheep to footrot.

. Australian Veterinary Journal 61:85-88.

Evans NJ, Brown JM, Demirkan I, Singh P, Getty B, Timofte D, Vink WD, Murray RD, Blowey RW, Birtles RJ, Hart CA, and Carter SD. 2009. Association of Unique, Isolated Treponemes with Bovine Digital Dermatitis Lesions. Journal of Clinical Microbiology 47:689-696. 10.1128/Jcm.01914-08

Frosth S, Konig U, Nyman AK, Pringle M, and Aspan A. 2015. Characterisation of Dichelobacter nodosus and detection of Fusobacterium necrophorum and Treponema spp. in sheep with different clinical manifestations of footrot. Veterinary Microbiology 179:82-90. 10.1016/j.vetmic.2015.02.034

Frosth S, Slettemeas JS, Jorgensen HJ, Angen O, and Aspan A. 2012. Development and comparison of a real-time PCR assay for detection of Dichelobacter nodosus with culturing and conventional PCR: harmonisation between three laboratories. Acta Veterinaria Scandinavica 54. Artn 6

10.1186/1751-0147-54-6

Graham NPH, and Egerton JR. 1968. Pathogenesis of Ovine footrot: The role of some environmental factors. . Australian Veterinary Journal 44:235-240.

Kaler J, Medley GF, Grogono-Thomas R, Wellington EM, Calvo-Bado LA, Wassink GJ, King EM, Moore LJ, Russell C, and Green LE. 2010. Factors associated with changes of state of foot conformation and lameness in a flock of sheep. Prev Vet Med 97:237-244. 10.1016/j.prevetmed.2010.09.019

Kennan RM, Wong W, Dhungyel OP, Han XY, Wong D, Parker D, Rosado CJ, Law RHP, McGowan S, Reeve SB, Levina V, Powers GA, Pike RN, Bottomley SP, Smith Al, Marsh I, Whittington RJ, Whisstock JC, Porter CJ, and Rood JI. 2010. The Subtilisin-Like Protease AprV2 Is Required for Virulence and Uses a Novel Disulphide-Tethered Exosite to Bind Substrates. Plos Pathogens 6. ARTN e100121010.1371/journal.ppat.1001210

Lange-Asschenfeldt B, Marenbach D, Lang C, Patzelt A, Ulrich M, Maltusch A, Terhorst D, Stockfleth E, Sterry W, and Lademann J. 2011. Distribution of bacteria in the epidermal 
434

435

436

437

438

439

440

441

442

443

444

445

446

447

448

449

450

451

452

453

454

455

456

457

458

459

460

461

462

463

464

465

466

467

468

469

470

471

472

473

474

475

476

477

478

479

480

481

482

483

layers and hair follicles of the human skin. Skin Pharmacol Physiol 24:305-311. 10.1159/000328728

Maboni G, Blanchard A, Frosth S, Stewart C, Emes R, and Totemeyer S. 2017a. A distinct bacterial dysbiosis associated skin inflammation in ovine footrot. Sci Rep 7:45220. 10.1038/srep45220

Maboni G, Davenport R, Sessford K, Baiker K, Jensen TK, Blanchard AM, Wattegedera S, Entrican G, and Totemeyer S. 2017b. A Novel 3D Skin Explant Model to Study Anaerobic Bacterial Infection. Front Cell Infect Microbiol 7:404. 10.3389/fcimb.2017.00404

Maboni G, Frosth S, Aspan A, and Totemeyer S. 2016. Ovine footrot: new insights into bacterial colonisation. Veterinary Record 179. 10.1136/vr.103610

Mendes HMF, Casagrande FP, Lima IR, Souza CH, Gontijo LD, Alves GES, Vasconcelos AC, and Faleiros RR. 2013. Histopathology of dairy cows' hooves with signs of naturally acquired laminitis. Pesquisa Veterinaria Brasileira 33:613-619. Doi 10.1590/S0100$736 \times 2013000500011$

Montes LF, and Wilborn WH. 1970. Anatomical Location of Normal Skin Flora. Archives of Dermatology 101:145-\&. DOI 10.1001/archderm.101.2.145

Moore LJ, Wassink GJ, Green LE, and Grogono-Thomas R. 2005. The detection and characterisation of Dichelobacter nodosus from cases of ovine footrot in England and Wales. Veterinary Microbiology 108:57-67. 10.1016/j.vetmic.2005.01.029

Nakatsuji T, Chiang HI, Jiang SB, Nagarajan H, Zengler K, and Gallo RL. 2013. The microbiome extends to subepidermal compartments of normal skin. Nature Communications 4. ARTN 1431

10.1038/ncomms2441

Refaai W, Ducatelle R, Geldhof P, Mihi B, El-shair M, and Opsomer G. 2013. Digital dermatitis in cattle is associated with an excessive innate immune response triggered by the keratinocytes. Bmc Veterinary Research 9. Artn 19310.1186/1746-6148-9-193

Roeckl H, and Mueller E. 1959. [A contribution to localization of skin microbes]. Arch Klin Exp Dermatol 209:13-29.

Stauble A, Steiner A, Frey J, and Kuhnert P. 2014. Simultaneous Detection and Discrimination of Virulent and Benign Dichelobacter nodosus in Sheep of Flocks Affected by Foot Rot and in Clinically Healthy Flocks by Competitive Real-Time PCR. Journal of Clinical Microbiology 52:1228-1231. 10.1128/Jcm.03485-13

Strub S, van der Ploeg JR, Nuss K, Wyss C, Luginbuhl A, and Steiner A. 2007. Quantitation of Guggenheimella bovis and treponemes in bovine tissues related to digital dermatitis. Fems Microbiology Letters 269:48-53. 10.1111/j.1574-6968.2006.00604.x

Tarlton JF, Holah DE, Evans KM, Jones S, Pearson GR, and Webster AJ. 2002. Biomechanical and histopathological changes in the support structures of bovine hooves around the time of first calving. Vet $J$ 163:196-204.

Thomas JH. 1962. Bacteriology and Histopathology of Footrot in Sheep. Australian Journal of Agricultural Research 13:725-\&. Doi 10.1071/Ar9620725

Wassink GJ, Grogono-Thomas R, Moore LJ, and Green LE. 2003. Risk factors associated with the prevalence of footrot in sheep from 1999 to 2000. Veterinary Record 152:351-358.

Wassink GJ, Grogono-Thomas R, Moore LJ, and Green LE. 2004. Risk factors associated with the prevalence of interdigital dermatitis in sheep from 1999 to 2000 . Veterinary Record 154:551-555.

Witcomb LA, Green LE, Calvo-Bado LA, Russell CL, Smith EM, Grogono-Thomas R, and Wellington EMH. 2015. First study of pathogen load and localisation of ovine footrot using fluorescence in situ hybridisation (FISH). Veterinary Microbiology 176:321-327. 10.1016/j.vetmic.2015.01.022 


\section{Figure 1}

Descriptors of leukocyte cell infiltration in ovine interdigital skin epidermis.

Haematoxylin and eosin stained epidermis photomicrographs showing no leukocytes in photomicrograph (A), occasional infiltration - single leukocytes visible within boxed areas (B), focal infiltration of leukocytes - visible in boxed areas (C), coalescing leukocytes - individual loci cannot be distinguished (D) and diffuse infiltration of leukocytes throughout the field of view (E). A-E represent inflammatory scores of $0-4$ respectively, $n=55$ healthy and 30 footrot. Scale bars represent $50 \mu \mathrm{m}$. 

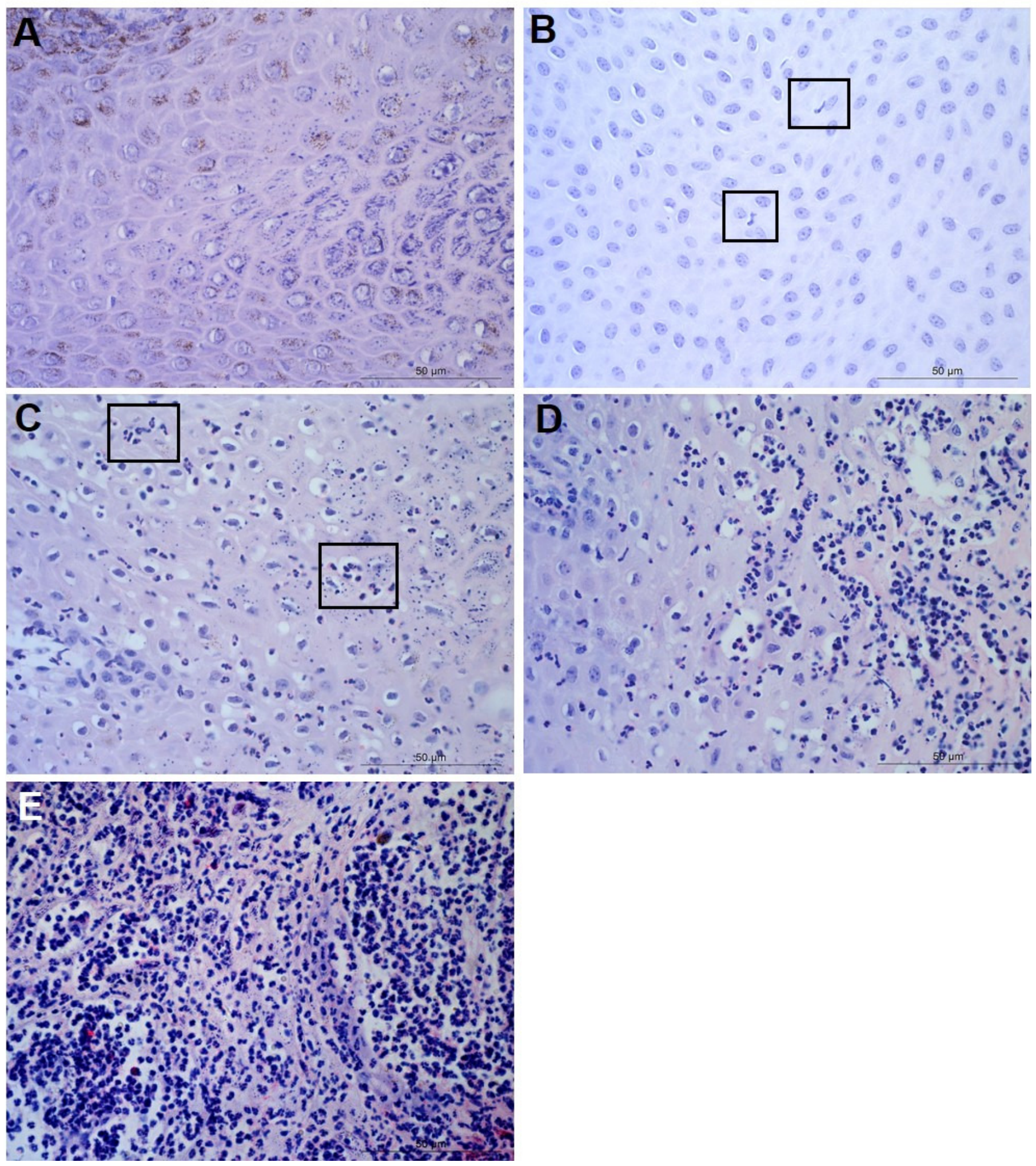


\section{Figure 2}

Descriptors of leukocyte cell infiltration in ovine interdigital skin dermis.

Haematoxylin and eosin stained dermis photomicrographs showing no leukocytes in photomicrograph (A), occasional infiltration of leukocytes (B), focal infiltration of leukocytes visible within boxed areas (C), coalescing leukocytes - individual loci cannot be distinguished (D) and diffuse infiltration of leukocytes throughout the field of view (E). A-E represent inflammatory scores $0-4$ respectively, $n=54$ healthy and 29 footrot. Scale bars represent $50 \mu \mathrm{m}$. 

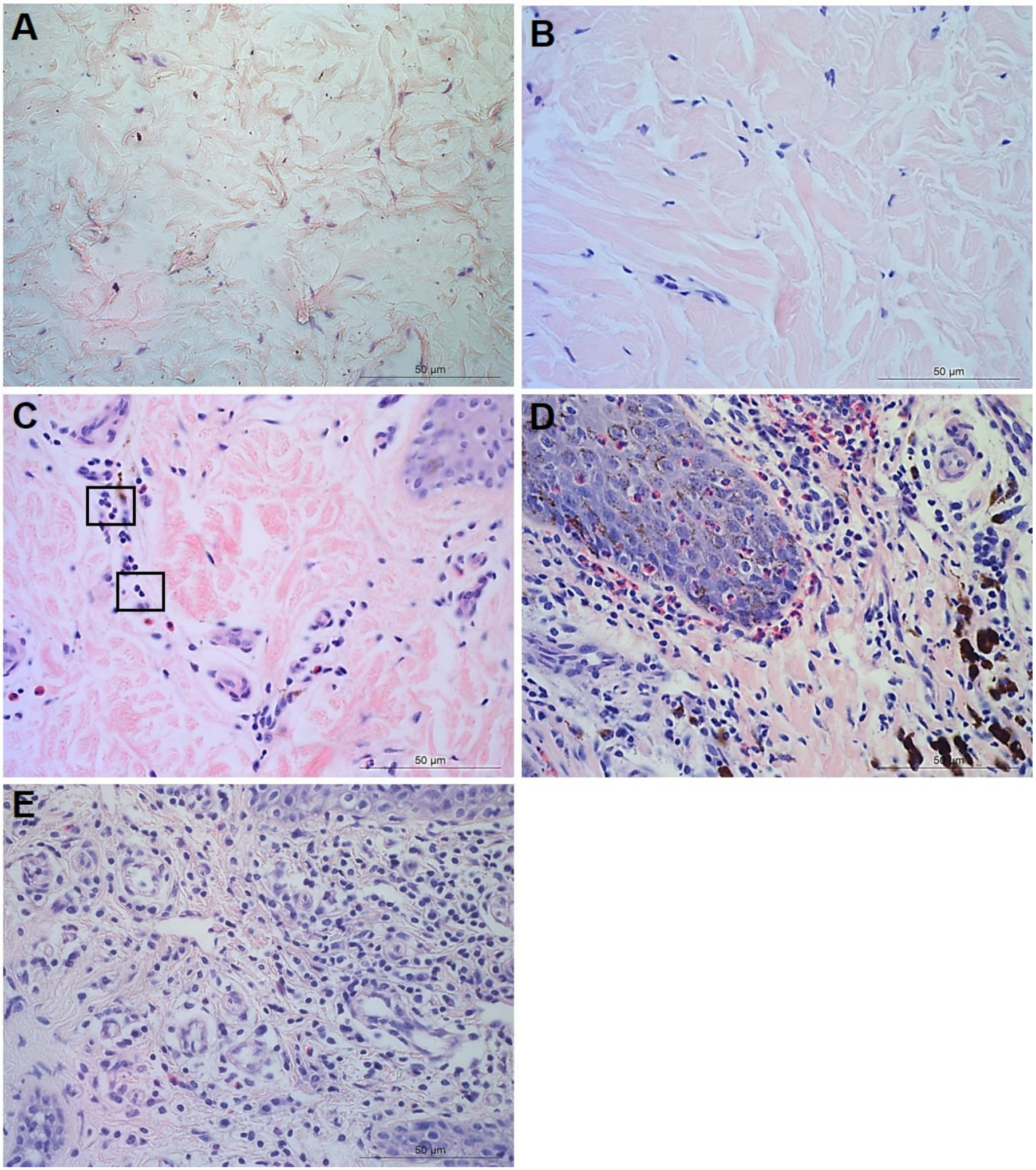


\section{Figure 3}

Descriptors of parakeratosis and micro-abscesses in ovine interdigital skin.

Haematoxylin and eosin stained interdigital skin from healthy $(n=55)$ and footrot $(n=30)$ affected sheep. Stratum corneum photomicrographs showing no nuclear remnants visible (A), focal accumulation of nuclear remnants (B) and diffuse accumulation of nuclear remnants (C). A-C represent parakeratosis scores $0-2$ respectively. Representative photomicrographs of micro-abscesses from the intra-corneal (D), sub-corneal (E) and dermal layers (F). Scale bars represent $50 \mu \mathrm{m}$.
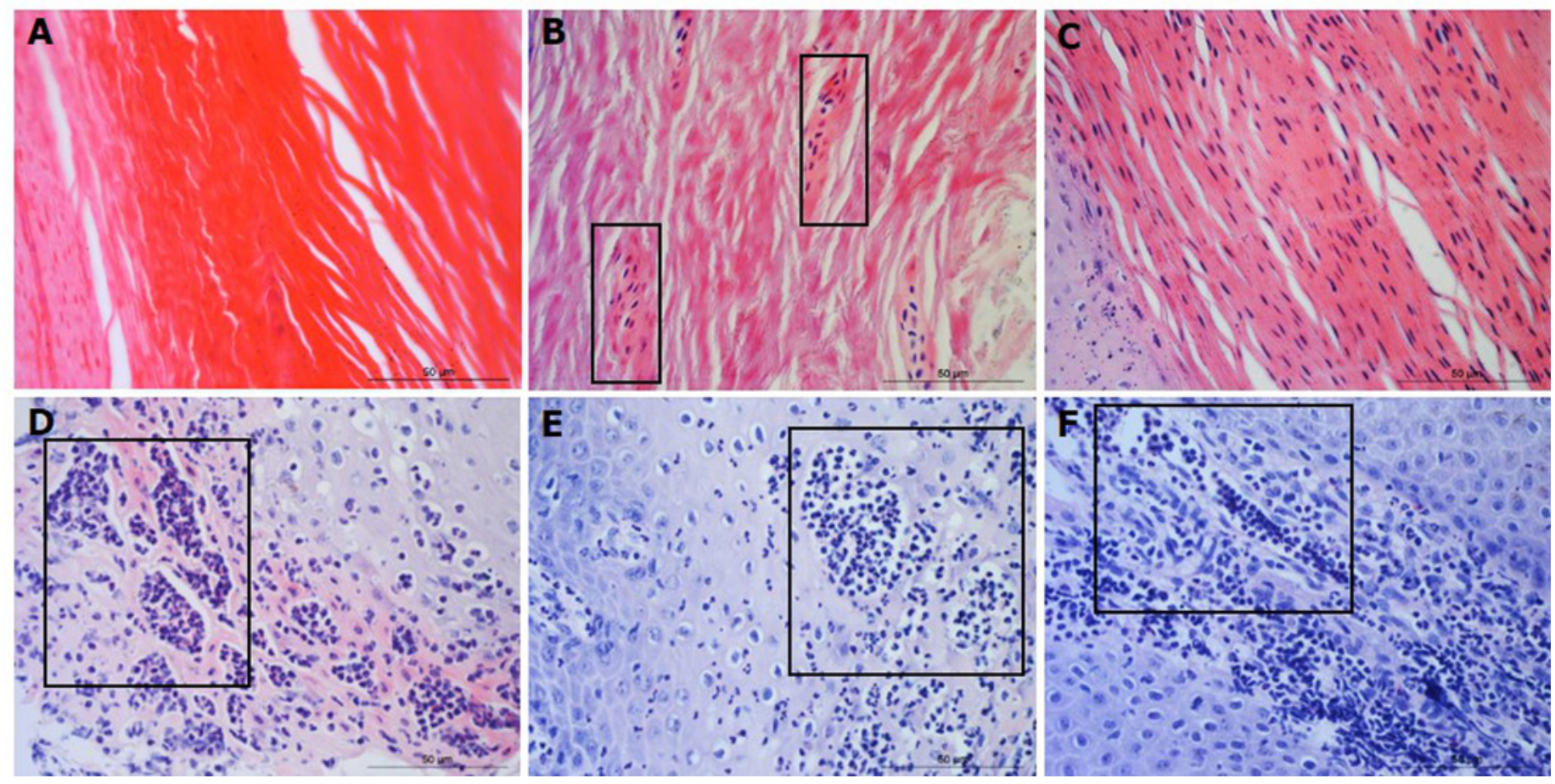


\section{Figure 4}

Interdigital skin cell ballooning, congestion and basement membrane integrity.

Haematoxylin and eosin stained sections from healthy $(n=55)$ and footrot $(n=30)$ affected sheep showing representative cell balloon measurements (A), congestion (B) and haemorrhage (C). PAS stained tissue shows basement membrane integrity scoring from 0 to 2 (D-E respectively).
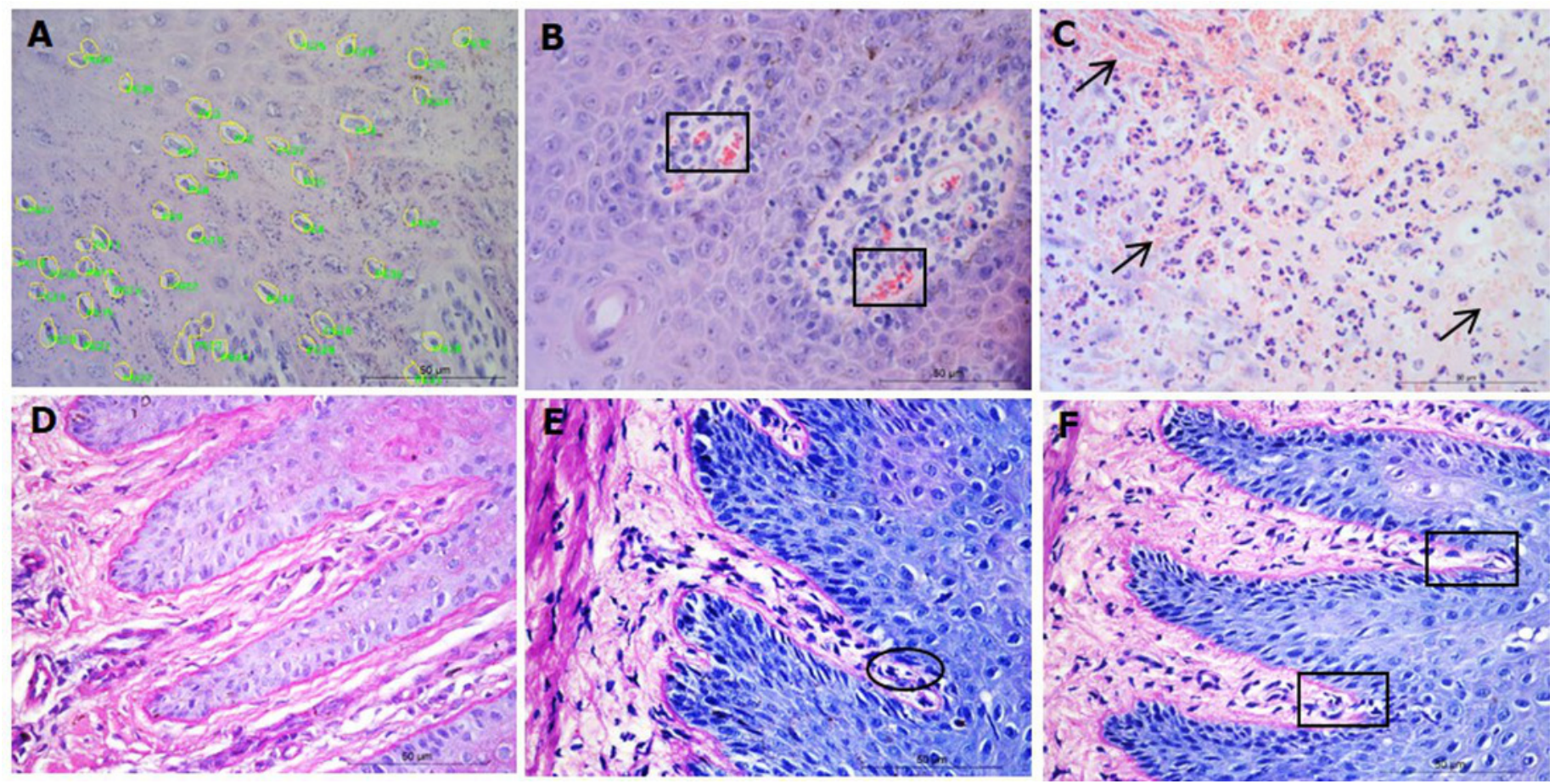


\section{Figure 5}

Epidermal histological lesions of ovine interdigital skin basal membrane integrity.

Haematoxylin and eosin stained sections from 55 clinically healthy and 30 footrot tissue samples of skin/hoof interface were evaluated with regards to inflammatory score (A), area of cell ballooning (B), presence of intra-corneal micro-abscesses (C), presence of sub-corneal micro-abscess (D), parakeratosis score (E). PAS stained sections from the same tissues were scored for disruptions of the basement membrane (F). The horizontal black line indicates median (A) and mean (B) values. Statistical analysis: Fisher's exact test (A, C-E) and one-way ANOVA (B). 
A

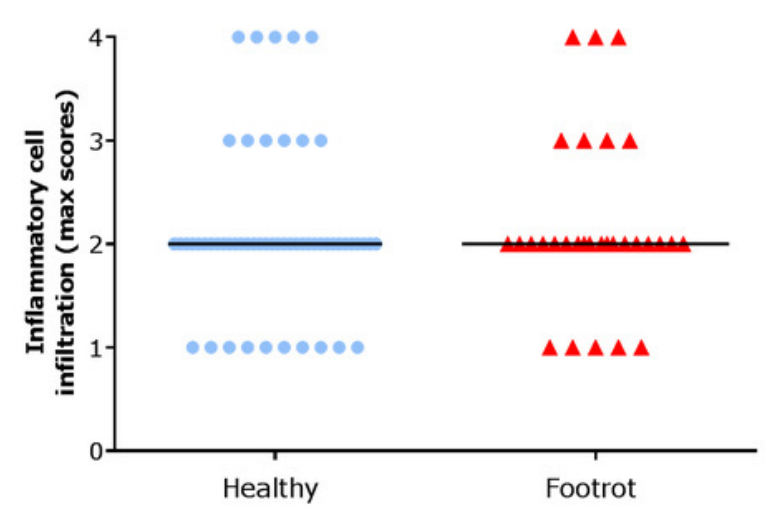

C

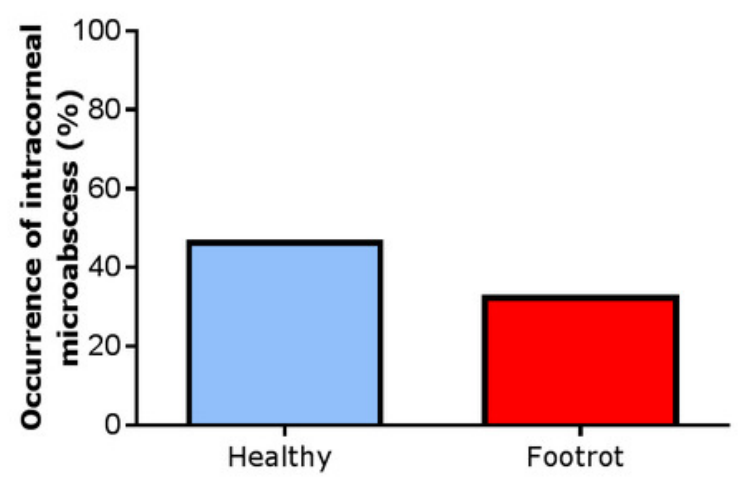

E

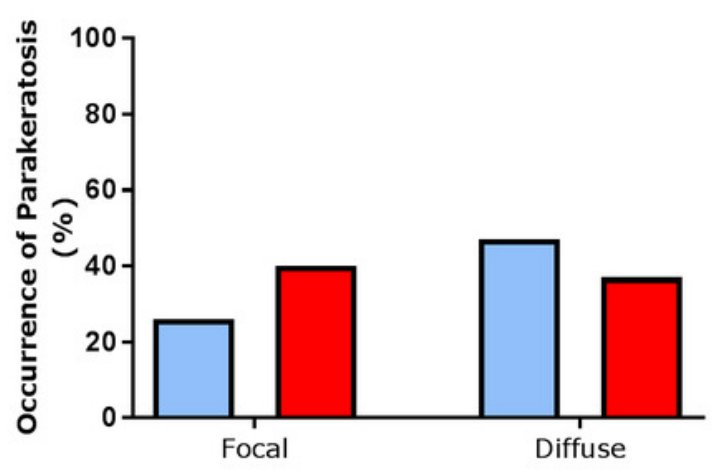

B

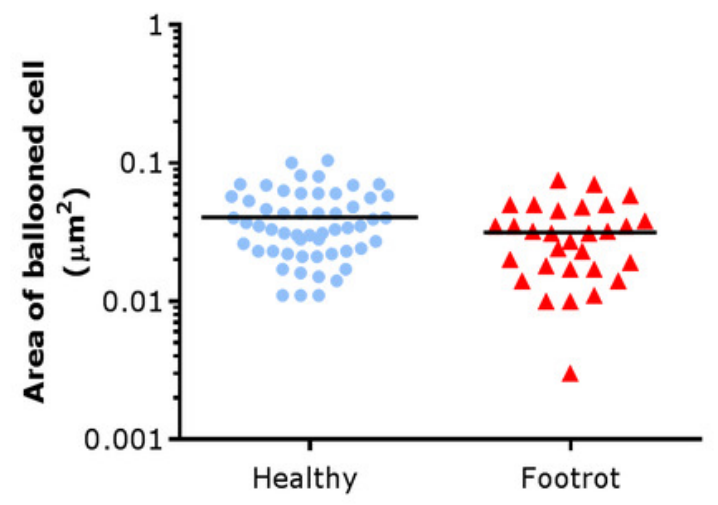

D

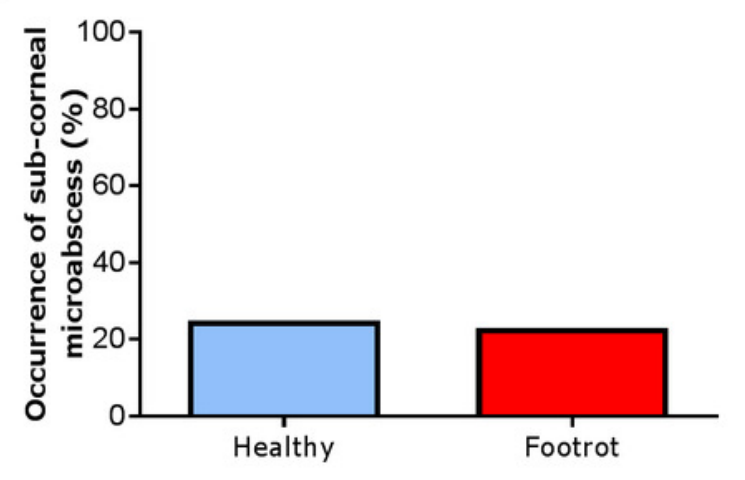

$\mathrm{F}$

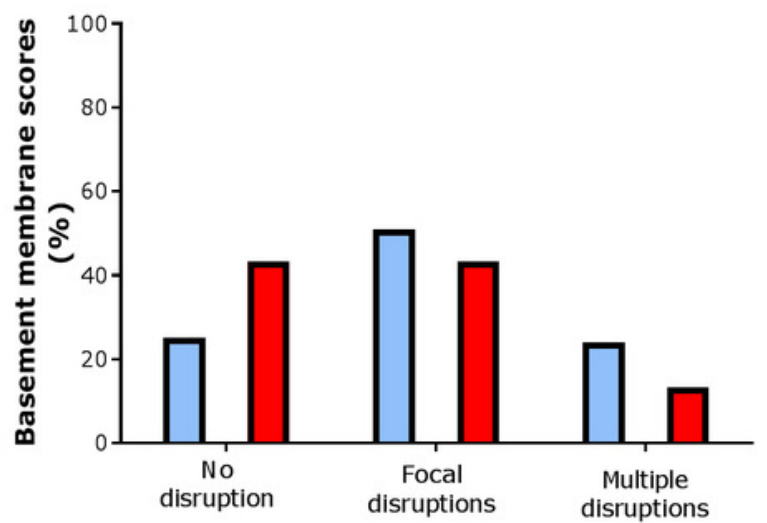




\section{Figure 6}

Dermal histological lesions of ovine interdigital skin.

Haematoxylin and eosin stained sections from 55 clinically healthy and 30 footrot tissue samples of skin/hoof interface were evaluated with regards to inflammatory score (A), presence of dermal micro-abscesses (B) haemorrhages (C) and congested blood vessels (D). The horizontal black line indicates median (A) values. Statistical analysis: Fisher's exact test.

A

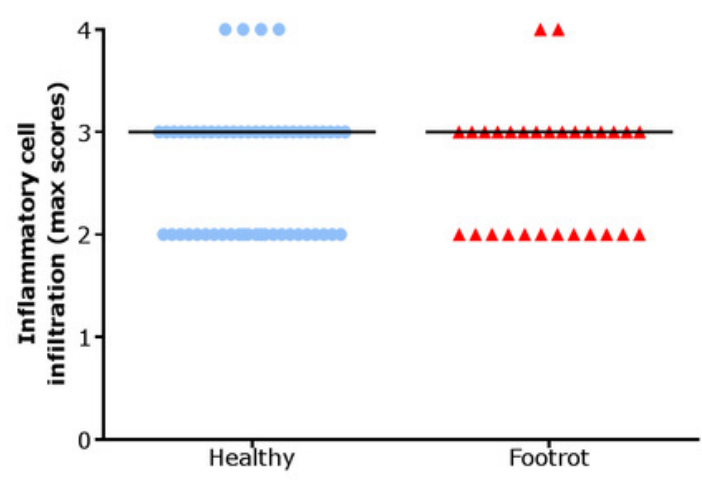

C

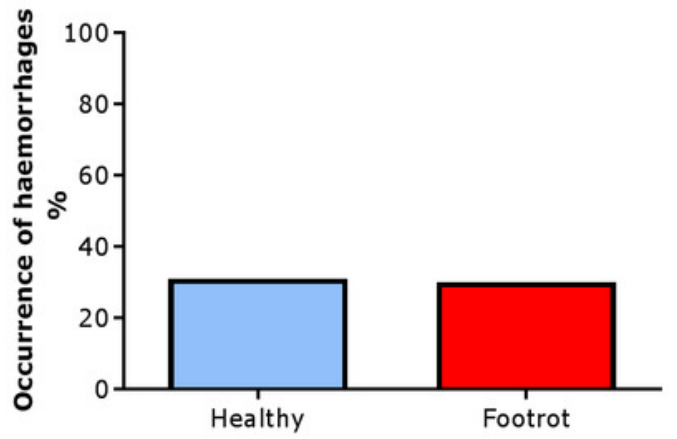

B

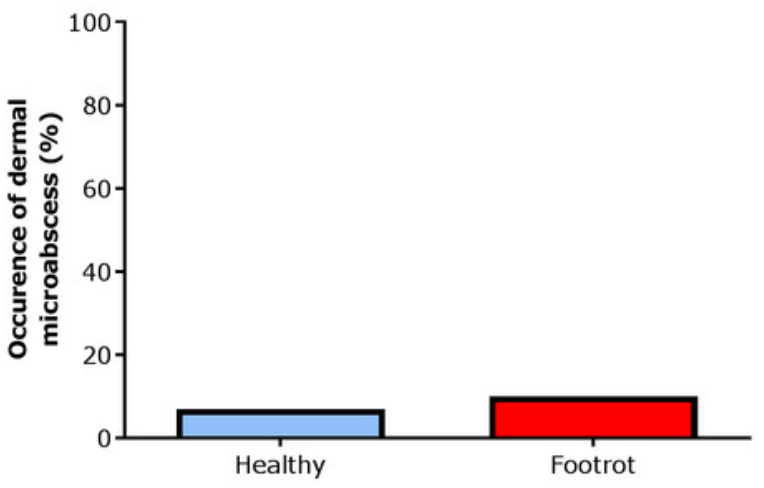

D

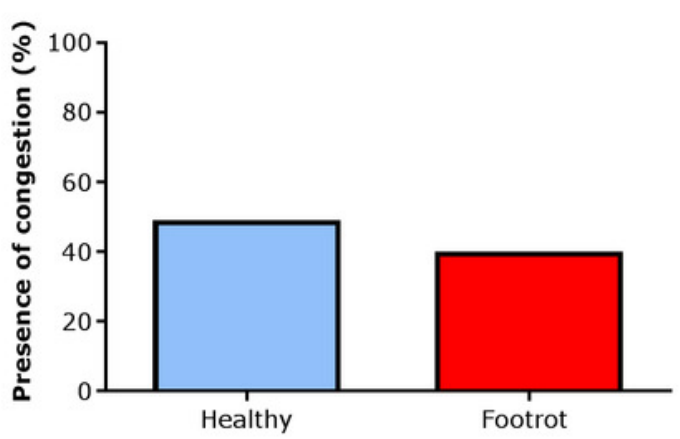




\section{Figure 7}

Comparison between IL-1 $\beta$ mRNA expression and parakeratosis score in ovine interdigital skin.

Correlation between IL-1 $\beta$ mRNA expression and parakeratosis score calculated from Haematoxylin and eosin stained samples of skin/hoof interface using parallel sections from the same interdigital space. $n=41$ clinically healthy and 23 footrot samples. Statistical analysis: Pearson correlation ${ }^{* *} p<0.01$.
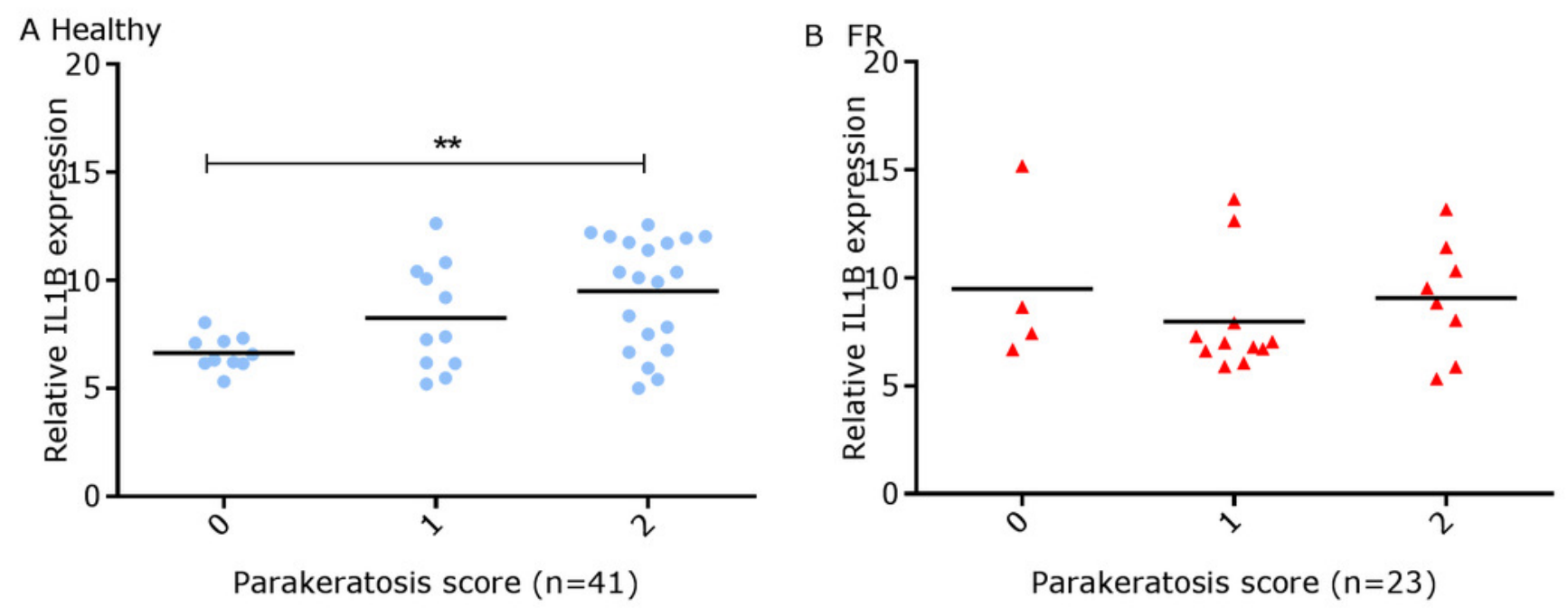


\section{Figure 8}

Comparison between IL-1 $\beta$ mRNA expression and epidermal and dermal inflammatory score in ovine interdigital skin.

Correlation between IL-1 $\beta$ mRNA expression and inflammatory score calculated from Haematoxylin and eosin stained samples of skin/hoof interface using parallel sections from the same interdigital space. $n=41$ clinically healthy and 23 footrot from the epidermis and 40 and 23 respectively from the dermis. Statistical analysis: Pearson correlation $* \mathrm{P}<0.05$.

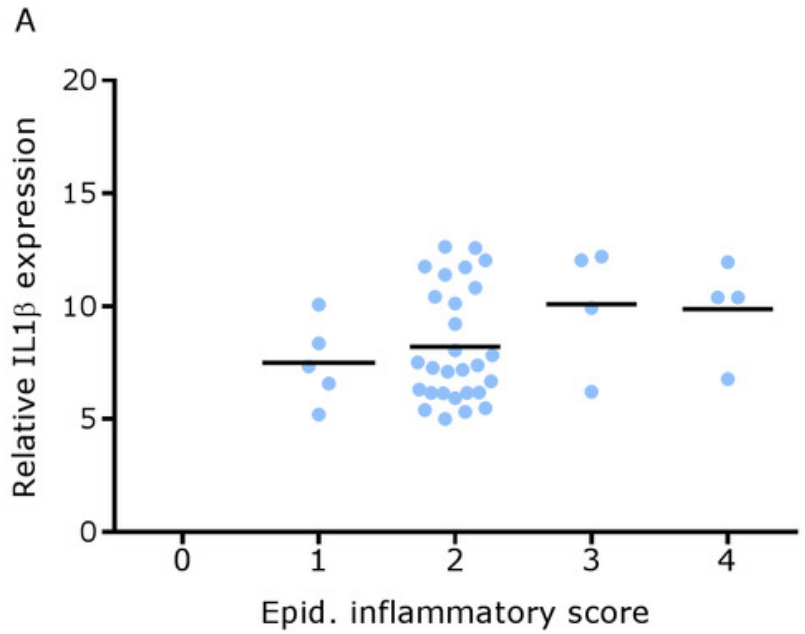

B

C

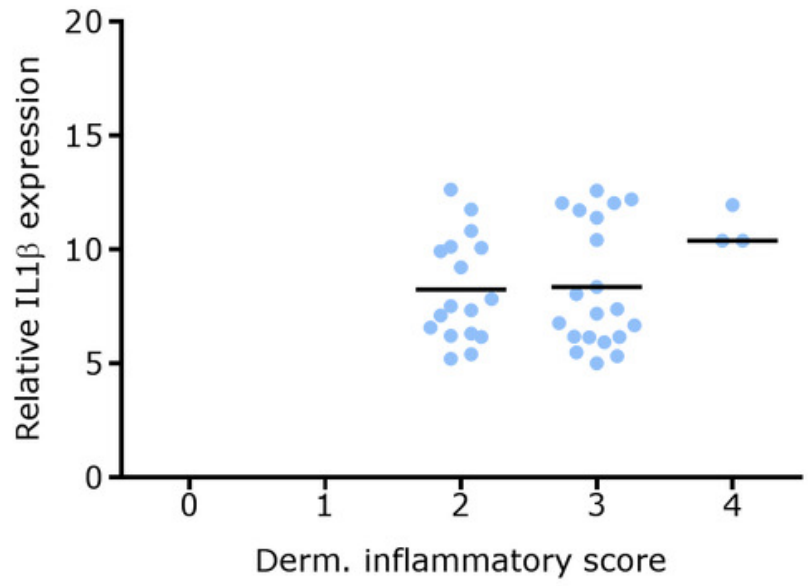

$\mathrm{D}$

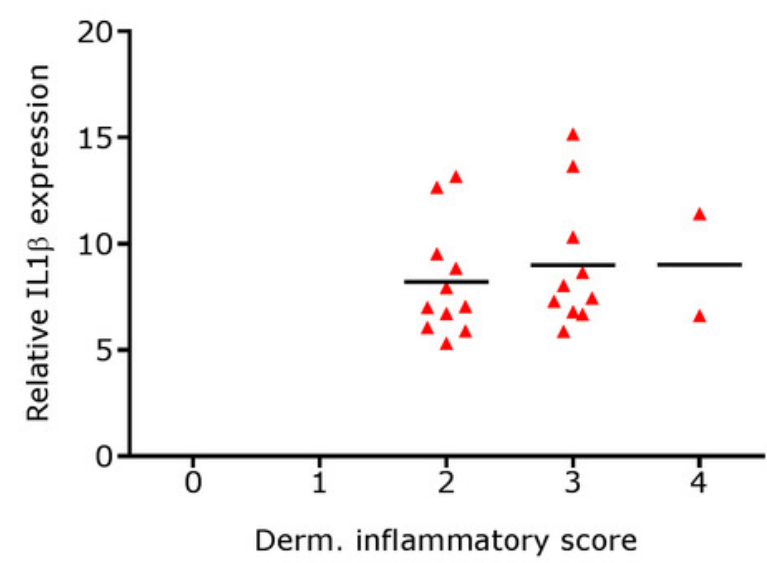


Figure 9

Virulent $D$. nodosus DNA levels in comparison to inflammatory scores in epidermal and dermal ovine interdigital skin.

Correlation between epidermal and dermal inflammatory scores from healthy $(n=30)$ and footrot samples ( $n=18$ epidermis and 17 dermis) in comparison to $D$. nodosus levels. Statistical analysis: Pearson correlation $* * * P<0.0001$.

A

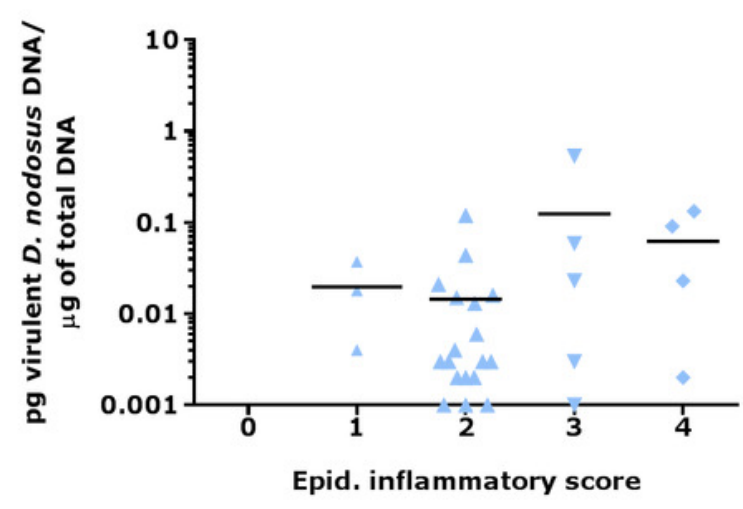

C

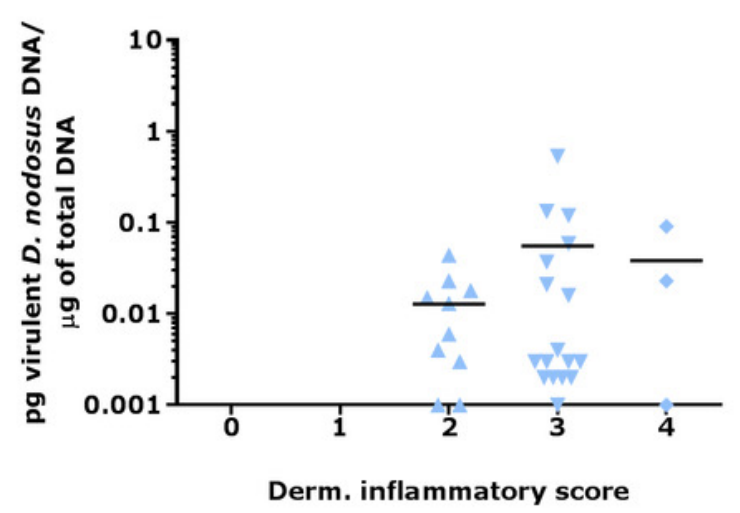

B

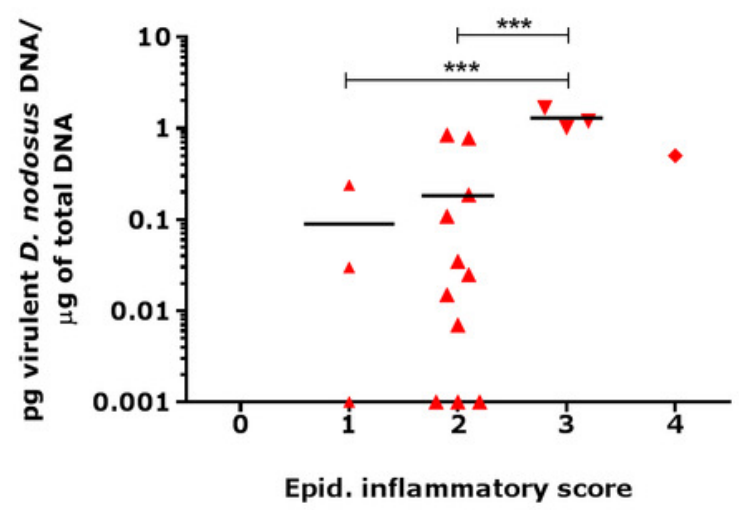

D

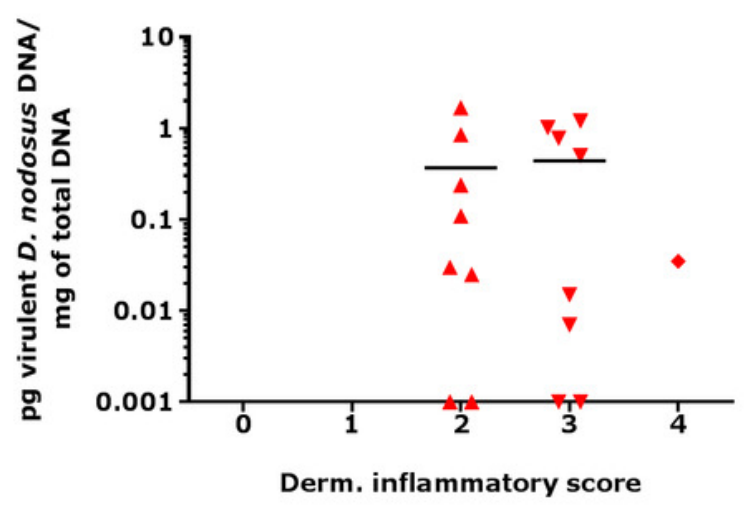




\section{Figure 10}

Bacterial localisation throughout skin layers.

Total DNA was extracted from sequential $40 \mu \mathrm{m}$ horizontal sections of $6 \mathrm{~mm}$ punch biopsies of from four healthy (A) and five footrot (B) affected tissue samples. Quantitative PCR was used to enumerate total bacterial DNA end detect the presence or absence of $D$. nodosus and $F$. necrophorum. Sections were grouped in $200 \mu \mathrm{m}$ bins.

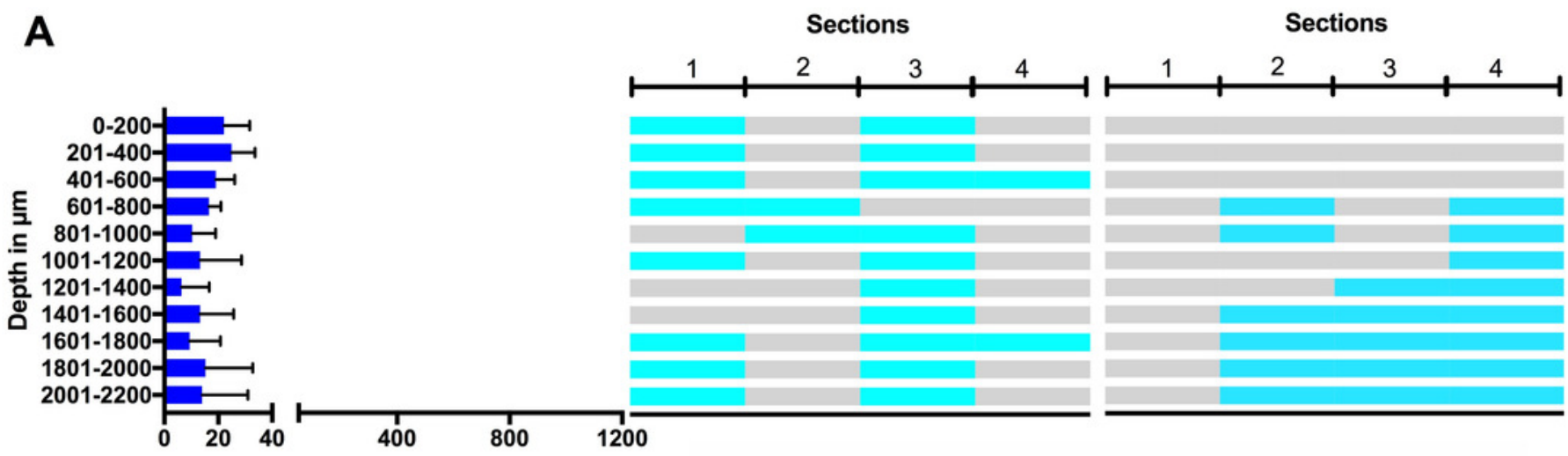

B

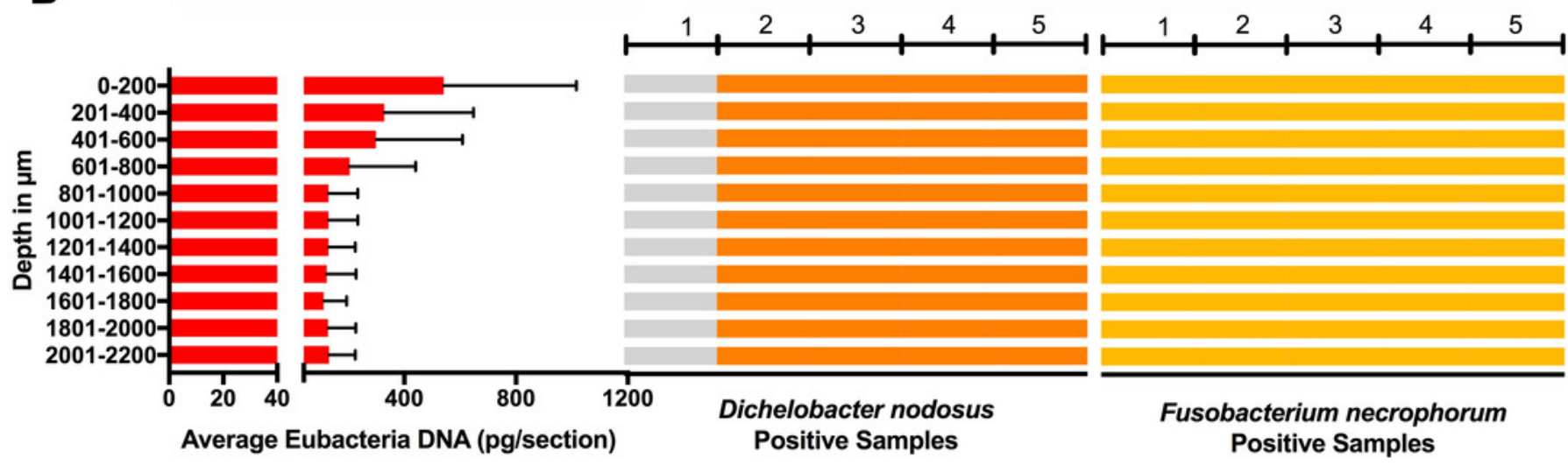

